\title{
Synthesis and Characterization of $\left[(\mathrm{PbSe})_{1+\delta}\right]_{4}\left[\mathrm{TiSe}_{2}\right]_{4}$ Isomers.
}

Danielle M. Hamann, Sage R. Bauers ${ }^{\perp}$, Aaron M. Miller, Jeffrey Ditto, Daniel Moore, and David C. Johnson*.

\section{Present Addresses}

Department of Chemistry and Materials Science Institute, University of Oregon, Eugene, Oregon 97403, USA

${ }^{\perp}$ Materials Science Center, National Renewable Energy Laboratory, Golden, Colorado 80309, USA

Corresponding Author

Email: davej@uoregon.edu

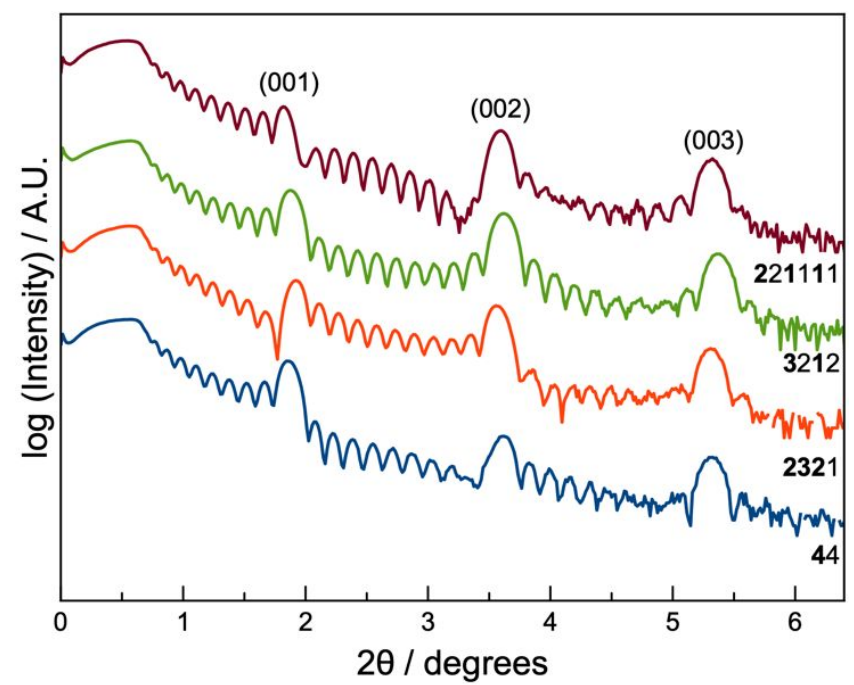

Figure S1. Representative as-deposited XRR patterns demonstrating the initial layering and rearrangement occurring in the sample before annealing occurs.

Table S1. Total Film thickness and repeat layer thickness for representative $\left[(\mathrm{PbSe})_{1+\delta}\right]_{4}\left[\mathrm{TiSe}_{2}\right]_{4}$ isomer heterostructures.

\begin{tabular}{ccc}
\hline Isomer & $\begin{array}{c}\text { As-Deposited } \\
\text { Total Film } \\
\text { Thickness }(\AA)\end{array}$ & $\begin{array}{c}\text { As-Deposited } \\
\text { Repeat } \\
\text { Thickness }(\AA)\end{array}$ \\
\hline 221111 & 557 & 49.34 \\
211211 & 545 & 49.05 \\
3311 & -- & -- \\
3212 & 546 & 49.34 \\
2321 & 544 & 50.81 \\
44 & 553 & 49.19 \\
\hline
\end{tabular}

The as-deposited total thickness was obtained from BedeREFS by assuming an 11-layer isomer block with no impurities and varying the c-lattice parameter of the isomer block until the simulated Kiessig fringes between $\theta_{\mathrm{c}}$ and the 001 reflection maxima matched those of the experimental XRR pattern. The simulated electron density was scaled by a factor of $0.9-0.95$ to 
get a precise match for the experimental $\theta_{\mathrm{c}}$. The as-deposited repeat unit thickness was calculated using a modified version of Bragg's Law corrected for refraction, and the first two Bragg reflections observed in the low angle diffraction patterns.

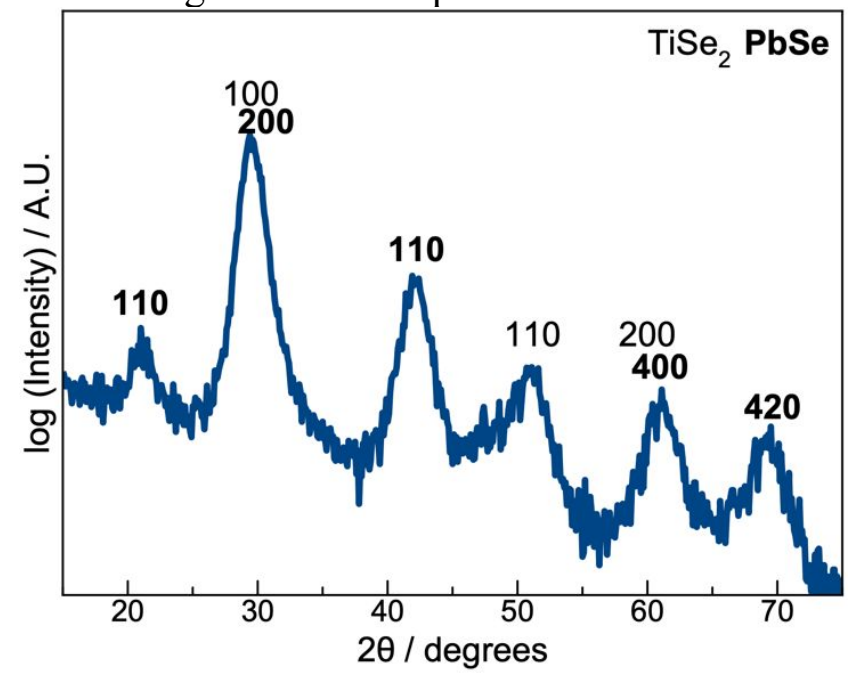

Figure S2. Representative grazing incidence in-plane diffraction of an as-deposited $\left[(\mathrm{PbSe})_{1+\delta}\right]_{1}\left[\mathrm{TiSe}_{2}\right]_{1}$ heterostructure demonstrating the initial nucleation of both $\mathrm{PbSe}$ and $\mathrm{TiSe}_{2}$ crystallites before annealing.
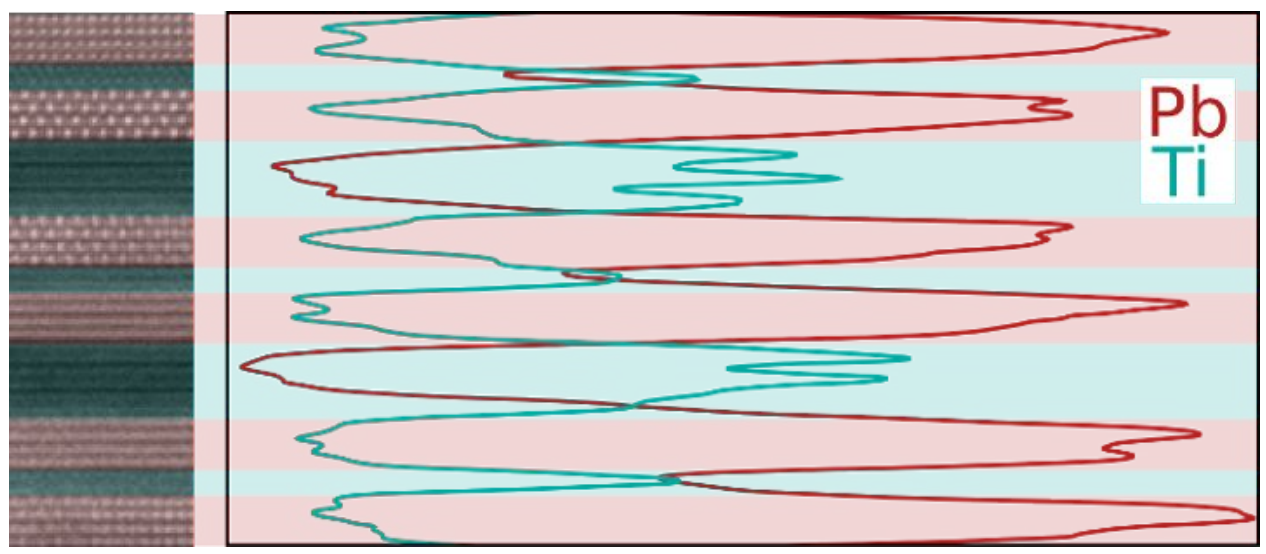

Figure S3. STEM-EDS showing the relative intensity of characteristic X-ray signals from $\mathrm{Pb}$ and $\mathrm{Ti}$ when moving down the $k=2321$ structure. 